\title{
Yb: YAG laser welding of Ti6Al4V sheet using conventional and annular power density distribution: microstructure mechanical properties relationship
}

\author{
J.-D. Béguin ${ }^{a}$, Y. Balcaen ${ }^{\text {a }}$, J. Alexis ${ }^{a}$, V. Gazagne ${ }^{a}$ and E. Andrieu ${ }^{b}$ \\ ${ }^{a}$ Université de Toulouse, LGP, ENIT/INPT, 47 Avenue d'Azereix, 65016 Tarbes, France \\ $\mathrm{b}^{\mathrm{b}}$ Université de Toulouse, Institut CARNOT CIRIMAT, UPS/CNRS/INPT, ENSIACET, 4 allée Emile Monso, 31030 Toulouse, France \\ Corresponding author: yannick.balcaen@enit.fr
}

\begin{abstract}
$\underline{\text { Abstract }}$
Development of high power laser beams with increasing beam quality and decreasing purchase cost lead to a strong development of laser welding techniques. Narrow weld beads, high welding speed, and low heat input are the main advantages of this reliable and repeatable joining process. The aim of this study is to investigate properties of weld seam obtained by Gaussian and annular power distribution, on butt joints of 0.9 mm annealed Ti6Al4V sheet by mean of an experimental design varying power level, spot size and shape, welding speed, and face gaseous protection flow. Examined characteristics of the weld seams are geometrical (Fusion Zone FZ and Heat Affected Zone HAZ shapes and dimensions, defects like porosities, undercut and underfill, distorsions of welded plates), microstructural (FZ and HAZ nature and morphology) and mechanical (tensile test, hardness filiations). Major features concerning the use an annular power distribution concern the flawless weld seam geometry and fair mechanical properties, with relatively low levels of distortions due to residual stresses.
\end{abstract}

\section{1 - Introduction}

Laser welding is a well-known technique to perform reliable assemblies in many industrials areas. Main advantages of this process is to propose relatively high welding speeds, minimal heat input and subsequently a minimal heat affected material, and high levels of flexibility. Continuous improvements in beam quality, versatility of equipment and in particular the emergence of $\mathrm{Yb}$ : YAG disk technology allows developments of new approaches in welding techniques [1-2]. In this particular case, the effects of size and shape of the focused spot on welding performances were scarcely investigated. Varying focused spot size allows independent modulation of power density (welding mode) and interaction time, without defocusing the beam. This feature could be a way to overcome thin sheets welding specific issues, namely a narrow process window. General issues related to Ti-6Al-4V laser welding are mainly both formation of hard $\alpha$ ' martensite in fusion zone, and a high sensitivity to oxygen and nitrogen contaminations, that can to brittleness of assemblies [3-4]. This work deals with butt joint welding of thin sheets of Ti-6Al-4V titanium alloy, and interprets effects of these new process parameters on microstructures and mechanical properties of obtained seams.

\section{$\underline{2 \text { - Experimental methods }}$}

The base material of the study is a $0.9 \mathrm{~mm}$ thick sheet of titanium Ti-6Al-4V alloy, fully annealed. The microstructure of this alloy consists in fine $\alpha$ equiaxed grains (approx. $10 \mu \mathrm{m}$ ) with very thin $\beta$ phase localized at $\alpha$ grain boundary. The titanium plates were obtained by laser cutting, and their edges were ground to ensure a minimal gap during positioning on the welding fixture. After a mechanical polishing with P600 SiC paper, samples were cleaned with acetone to remove grease and lubricant contaminations.

The laser apparatus employed in this study is a TrulaserCell 3000 laser cutting and welding machine produced by TRUMPF. The beam is produced by a 3 $\mathrm{kW}$ Yb: YAG disk laser source, equipped with a 2 in 1 coaxial fiber which is delivering the beam through special optics. These optics permit to focus the laser spot and adapt its size without defocusing. The position of the focused spot is also adjustable by few millimeters back or forth the nominal focusing length. The "2 in 1" optical fiber, with a remotely activated fiber selector, allows to process with two distinctive power distribution. Outer fiber generates an annular power density distribution, with a top-hat profile, whereas core fiber delivers a near Gaussian power distribution. In the following, these power density distributions will be referenced as Outer fiber and Core fiber.

Experimental design proposed in this study was already used in previous work [5]. This experimental design was established with the CORICO ${ }^{\circledR}$ software [6] and involves varying welding speed, laser power, focus spot diameter and shape, and argon protection flow, as detailed in table 1.

Table 1 : Experimental Design matrix defined by the CORICO® software.

\begin{tabular}{|c|c|c|c|}
\hline \multicolumn{2}{|l|}{ Welding parameters } & \multirow{2}{*}{$\begin{array}{l}\text { Values } \\
500-2500 \text { (5 levels) }\end{array}$} & \multirow{2}{*}{$\begin{array}{l}\text { Others process parameters } \\
\text { Laser beam focused } 0.3 \mathrm{~mm} \text { under top surface }\end{array}$} \\
\hline Power & {$[\mathrm{W}]$} & & \\
\hline Welding Speed & {$[\mathrm{m} / \mathrm{min}]$} & $1-8$ (5 levels) & Argon root gas flow: $201 . \mathrm{min}^{-1}$ \\
\hline Argon face gas flow & {$[1 / \mathrm{min}]$} & $10-40$ (4 levels) & Welds length : $120 \mathrm{~mm}$ \\
\hline Focal Spot diameter & {$[\mu \mathrm{m}]$} & \multicolumn{2}{|c|}{$120-370$ for Core fiber ( 5 levels) and $480-750$ for Outer fiber } \\
\hline
\end{tabular}


Geometrical distortions were measured on welded sample with dial gauge, perpendicularly to the weld seam. Metallographic examinations were carried out on polished ( $10 \%$ vol. $\mathrm{H}_{2} \mathrm{O}_{2}$ in OPS suspension for final polishing) and etched (with Kroll's reagent) samples, using Olympus PMG-3 optical microscope. These cross sections obtained allowed to determine characteristics dimensions of seams: FZ and HAZ width on face, waist and root; amplitudes of undercuts, reinforcement and underfill. Hardness tests through these different zones were conducted with a ZHU 2.5 automatic instrumented hardness tester produced by Zwick, configured for HV0.3 tests, with $100 \mu \mathrm{m}$ spaced indents. Tensile tests were conducted perpendicularly to the weld seam, on three samples for each welded joint, with a crosshead speed of $2 \mathrm{~mm} \cdot \mathrm{min}^{-1}$. The tested sections are $10 \mathrm{~mm}$ wide and $0.9 \mathrm{~mm}$ thick, for a useful length of $25 \mathrm{~mm}$.

\section{$\underline{3}$ - Results and discussion}

\section{Weldability window}

All the following study will deal with fully penetrant weld seam only, and it is necessary to define a "weldability window" first. The welding domain is presented at figure 1, on an Interaction time vs Power density (or Irradiance) plot. The boundaries for sound welds using Core Fiber are a maximum interaction time of approx. $7-8 \mathrm{~ms}$ for a keyhole welding regime (obtained with a power density above $10^{6} \mathrm{~W} . \mathrm{cm}^{-2}$ ) and a minimum energy density of 4 $\mathrm{kJ} . \mathrm{cm}^{-2}$. This second boundary is less well-defined and could be only suggested. Welding under this level of energy density can lead to incomplete or unstable penetration of the weld. In conduction mode welding, mainly concerning the outer fiber, the weldability window could be described in terms of a power density maintained above $610^{5} \mathrm{~W} . \mathrm{cm}^{-2}$, and an energy density between 4 and $9 \mathrm{~kJ} . \mathrm{cm}^{-2}$. Attempting to weld above these proposed boundaries lead to catastrophic cut through with complete collapse of weld pool.

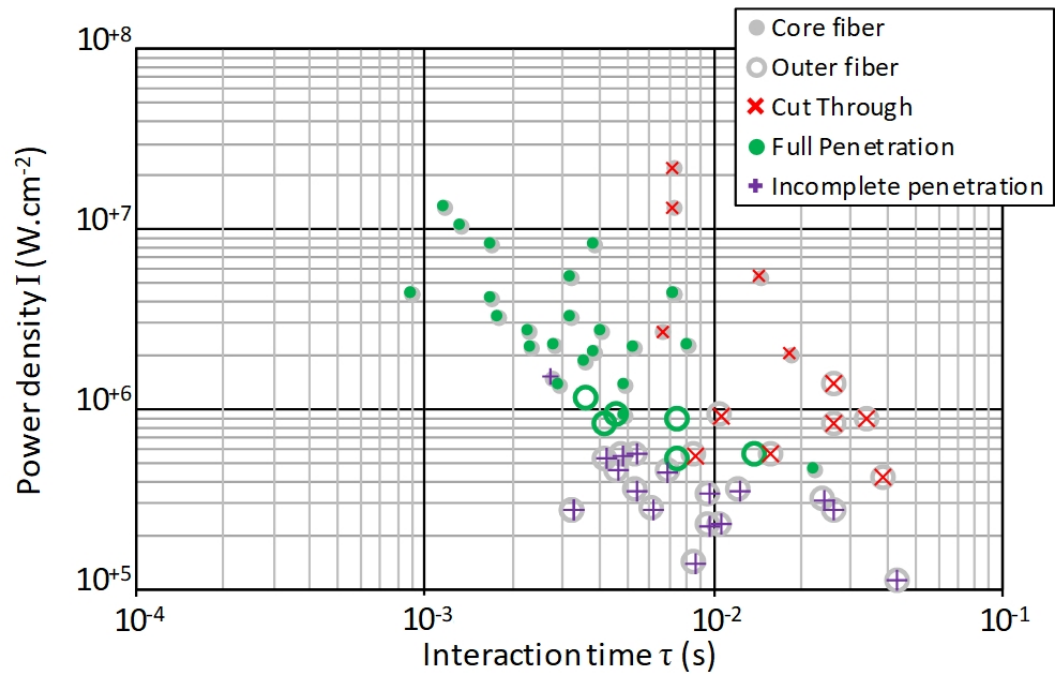

Figure 1: Interaction time - Power density plot of experimental design

Effect of process parameters on weld bead geometry

Microstructures of obtained weld beads (figure 2a) Fusion Zone (FZ) consists in fine, needle-shaped, $\alpha$ ' martensite in coarse prior $\beta$ grains (figure 2c). Heat Affected Zone (HAZ) microstructure is an increasing proportion of transformed $\beta$ phase to acicular $\alpha^{\prime}$ in vicinity of the FZ (figure 2 b).

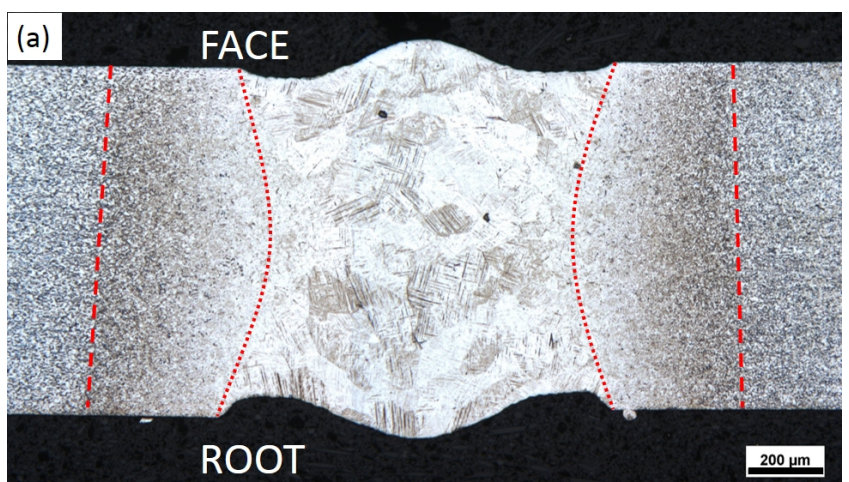



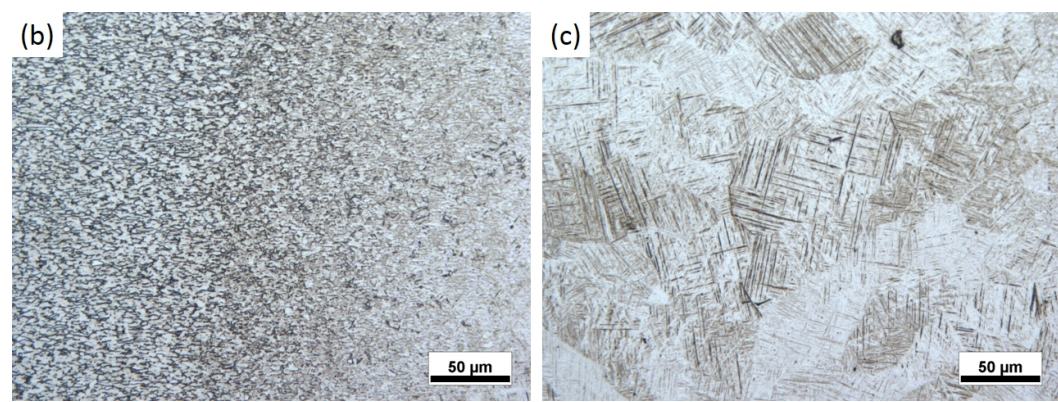

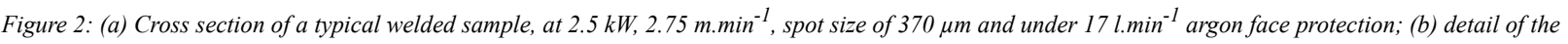
microstructure of the HAZ; (c) detail of the fusion zone

Considering fully penetrant weld seams, and to propose a reliable link between process parameter and geometry of obtained weld beads, it was found that interaction time was accurate variable to predict the width of weld affected zone (i.e. FZ + HAZ). The plot of weld width versus interaction time is presented at figure 3. To complete this assessment, a link has to be made between interaction time and power density. For high levels of irradiance, the melt pool is under keyhole regime. This welding mode is suitable to obtain deep penetrations in the case of thick metal sheets welding. Whereas, on thin sheets, it can lead to strong instabilities and, in the case of an excessive widening of the weld pool, a complete collapse of it. To avoid such phenomenon, high irradiance has to be used with high welding speeds. For low levels of power density, coupled conduction-convection welding mode is predominant, and is leading to necessary high levels interaction time to obtain full penetration, especially with outer fiber processing. Concerning the difference between Core fiber and Outer fiber welding, these two processing techniques seems to follow the same tendency.

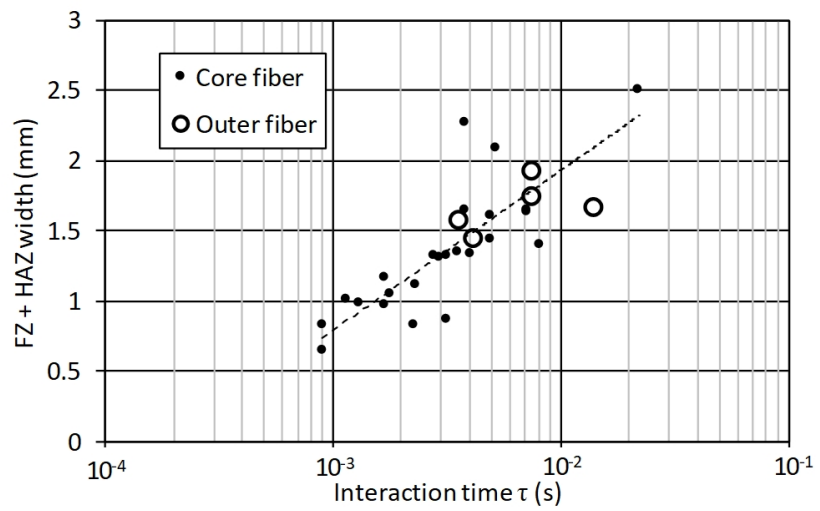

Figure 3: Weld affected width vs. interaction time plot

Effect of process parameter on geometrical defects

Underfill, or excessive reinforcement coupled with undercut, are the most encountered geometrical defects observed in laser welding. A unique parameter is proposed to describe such geometrical defects, adding amplitudes of undercut and reinforcement a, divided by the width of the fusion zone on face side $\mathrm{w}_{\mathrm{FZ}}$. As can be seen on figure 4, the power density could be the pertinent parameter to distinguish smooth weld geometries, obtained with power densities lower than $310^{6}$ W.cm ${ }^{-2}$, and higher probabilities to obtain critical geometrical defects for higher levels of power densities. Such observation can be positively linked with previously proposed keyhole induced instabilities. In this case also, Outer fiber and Core fiber do behave similarly.

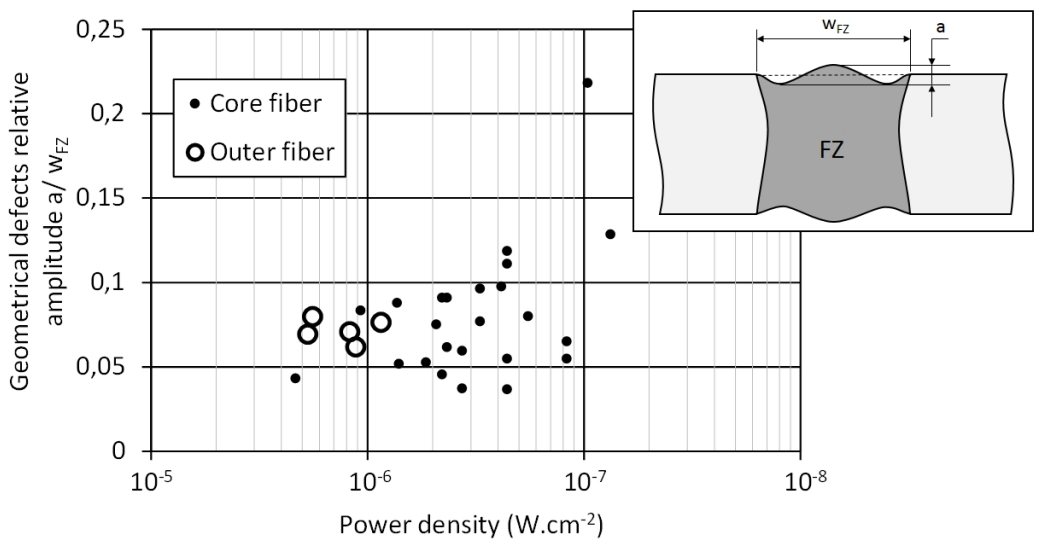

Figure 4: Relative amplitude of geometrical defects vs. power density plot

Generation of geometric distortions of welded plates

To qualify relative amplitudes of residual stresses in assemblies, it is proposed to measure, after welding and unclamping the curvature of plates. In order to simplify the approach, deflection and angle of transvers bending were related to processing parameters or geometrical features. Although bending angle and deflection are following the same tendency, the most relevant correlation was found between the width of the fusion zone at the waist, and the deflection of the plate (figure 5). 


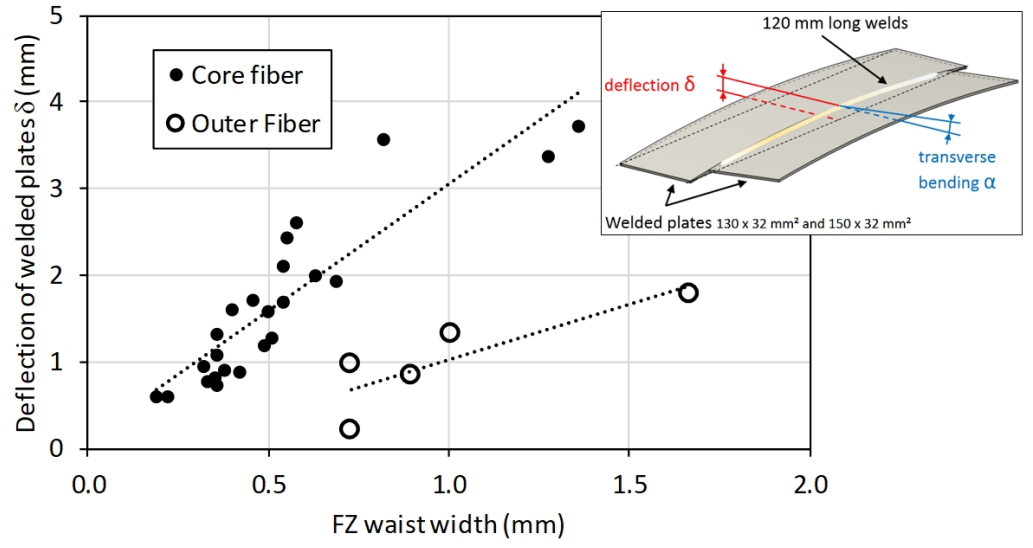

Figure 5: Geometrical deflection of welded plates vs. FZ waist width plot

In this case, Core fiber and Outer fiber exhibit a clearly different behavior. Outer fiber welding produce clearly less distorted assemblies. This observation could be explained by the fact that Outer fiber welding implies low levels of irradiance, coupled with high interaction times. The consequence is less abrupt temperature gradients compared to keyhole welding mode and a relatively low cooling rate. Hence, levels and components of residual stress could be strongly different from classical keyhole welding mode.

Mechanical properties: Hardness \& Ductility

In this study, mechanical behavior of assemblies is explored through tensile test and completed by hardness tests on cross sections. The welded samples presented a similar behavior in terms of ultimate tensile strength, ranging from 994 to $1070 \mathrm{MPa}$ [7]. The significant differences were observed on ductility. The total elongation at fracture is strongly affected by the weld, and the global decrease compared to the base metal is due to a structural effect. Indeed, in the case of a fully penetrant weld, the weld bead plays the role of a stiffener, perpendicular to the tensile axis and, if sufficiently resistant, shift the fracture far from it [8]. This phenomenon leads to an apparent loss of ductility compared to the base metal. Concerning the low ductility observed on some samples (figure 6), it seems correlated to the low argon protective flow during their processing (10 1.min ${ }^{-1}$ ), that could be the cause of a possible interstitials pollution by oxygen and nitrogen. The concerned samples presented a fracture systematically situated in FZ.

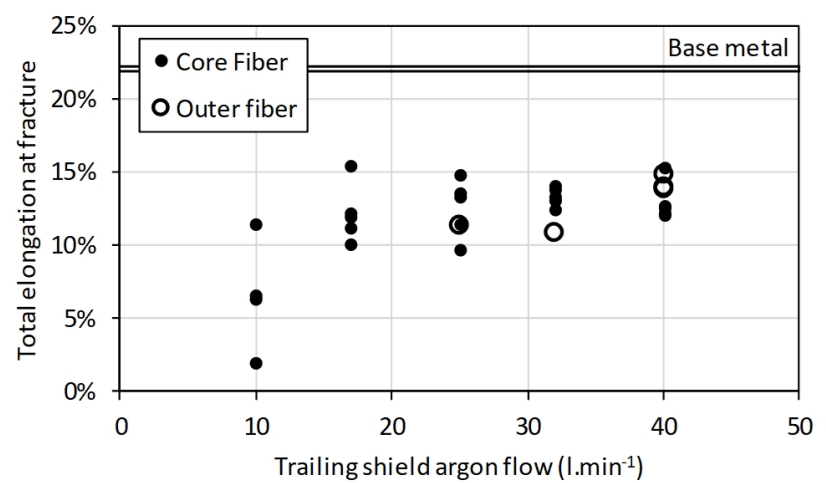

Figure 6: total elongation to fracture of welded samples at various argon shielding flow

Hardness tests revealed another aspect of process influence on mechanical properties. Low levels of interaction time (and associated high levels of irradiance) lead to high cooling rates in the fusion zone and the nearby HAZ, leading and vice versa for high interaction time (figure 7). This hypothesis could explain the observed decrease of hardness with increasing interaction time, by considering that martensite maximum hardness could be reached by high cooling rates [9].

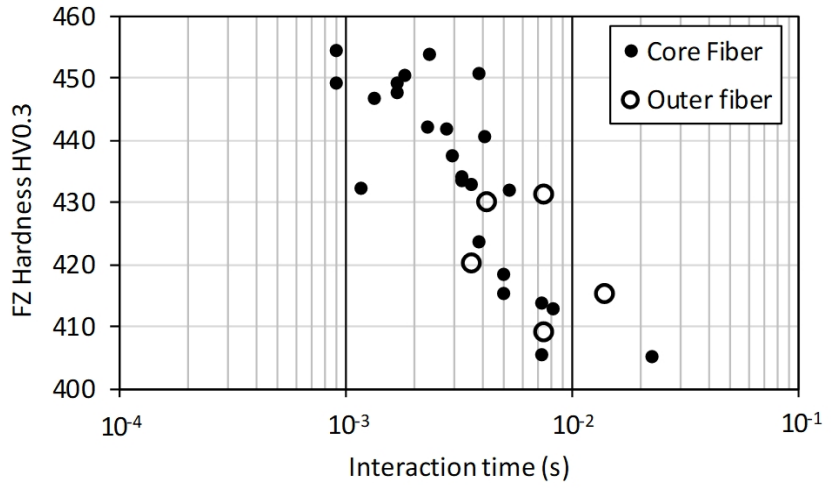

Figure 7: Evolution of mean Vickers Hardness HV0.3 as function of interaction time. 


\section{Conclusion}

The possibility offered by the controlled modulation of focused spot size and shape allowed to explore weldability domain and to highlight distinctive effects of process parameters on the welding of thin Ti-6Al-4V sheets. These can be summarized as:

1. The boundary of the welding domain is defined in terms of a minimum energy density of $4 \mathrm{~kJ} \cdot \mathrm{cm}^{-2}$ and a minimum irradiance of $610^{5} \mathrm{~W} . \mathrm{cm}^{-2}$. The upper boundaries are an interaction time maintained under 7 to $8 \mathrm{~ms}$ in keyhole welding mode, and a power density of $9 \mathrm{~kJ} . \mathrm{cm}^{-2}$ in conduction regime.

2. The minimum argon flow to ensure mechanical properties is found to be $101 \cdot \mathrm{min}^{-1}$, unless the low ductility of interstitial polluted martensitic fusion zone leads to noticeable decrease of mechanical properties.

3. Main advantages of Outer fiber processing are on low geometric distortions and expected levels of induced residual stresses. Other aspects, concerning mechanical properties, and geometrical defects, did not allowed to distinguish specific trends related to the use of annular power distribution. However, while the Outer fiber welding window appears narrower than the Core fiber one, annular power distribution provided satisfactory weld bead geometries, with a moderate FZ hardness.

\section{References}

[1] A. Giesen, and J. Speiser, IEEE J. Sel. Top. Quantum Electron. 13, (2007) 598-609.

[2] G. Verhaeghe, and B. Dance, Proc. Int. Conf of Appl. of Lasers and Electro-Opt., ICALEO, Temecula, USA, (2008) 406-414.

[3] A. Squillace et al., J. Mat. Proc. Tech. 212 (2012) 427-436.

[4] X. Cao, and M. Jahazi, Opt \& Laser Eng. 47 (2009) 1231-1241.

[5] J. Alexis et al., Mat. Sci. Forum. 941 (2018) 1099-1104

[6] M. Lesty, La revue de Modulad 22 (1999) 39-77.

[7] F. Caiazzo et al. J. Mat. Proc. Tech 149 (2004) 546-552

[8] B. Sarre et al., Procedia Struct. Integrity 2 (2016) 3569-3576

[9] V.C. Kumar, Surf. Coat. Tech. 201 (2006) 3174 